\title{
The rise in climate change-induced federal fishery disasters in the United States
}

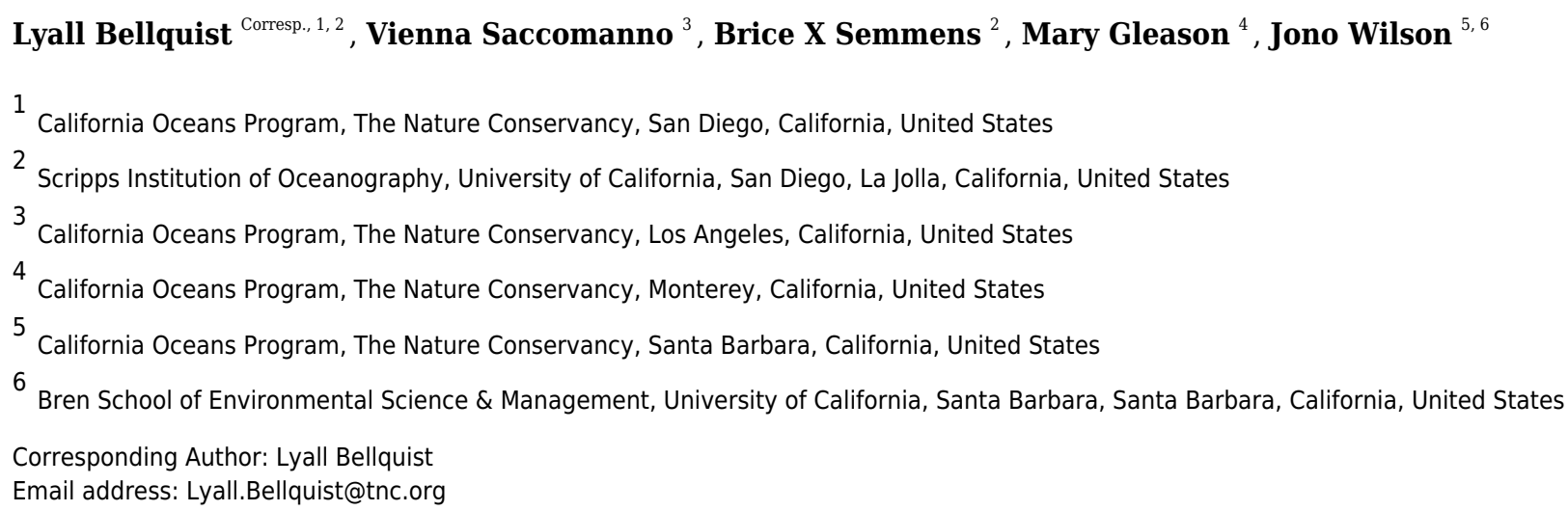

Commercial, recreational, and indigenous fisheries are critical to coastal economies and communities in the United States. For over three decades, the federal government has formally recognized the impact of fishery disasters via federal declarations. Despite these impacts, national syntheses of the dynamics, impacts, and causes of fishery disasters are lacking. We developed a nation-wide Federal Fishery Disaster database using National Oceanic and Atmospheric Administration (NOAA) fishery disaster declarations and fishery revenue data. From 1989-2020, there were 71 federally approved fishery disasters (eleven are pending), which spanned every federal fisheries management region and coastal state in the country. To date, we estimate fishery disasters resulted in \$2B (2019 USD) in Congressional allocations, and an additional, conservative estimate of \$3.2B (2019 USD) in direct revenue loss. Despite this scale of impact, the disaster assistance process is largely ad hoc and lacks sufficient detail to properly assess allocation fairness and benefit. Nonetheless, fishery disasters increased in frequency over time, and the causes of disasters included a broad range of anthropogenic and environmental factors, with a recent shift to disasters now almost exclusively caused by extreme environmental events (e.g., marine heatwaves, hurricanes, and harmful algal blooms). Nationwide, $84.5 \%$ of fishery disasters were either partially or entirely attributed to extreme environmental events. As climate change drives higher rates of such extreme events, and as natural disaster assistance requests reach an all-time high, the federal system for fisheries disaster declaration and mitigation must evolve in order to effectively protect both fisheries sustainability and societal benefit. 
1 The rise in climate change-induced Federal Fishery

2 Disasters in the United States

3

4 Lyall Bellquist ${ }^{1,2}$, Vienna Saccomanno ${ }^{3}$, Brice X. Semmens ${ }^{2}$, Mary G. Gleason ${ }^{4}$, Jono Wilson ${ }^{5,6}$ 5

$6 \quad{ }^{1}$ California Oceans Program, The Nature Conservancy, San Diego, California, United States

7 '2 Scripps Institution of Oceanography, University of California San Diego, La Jolla, California, 8 United States

$9{ }^{3}$ California Oceans Program, The Nature Conservancy, Los Angeles, California, United States

$10{ }^{4}$ California Oceans Program, The Nature Conservancy, Monterey, California, United States

$11{ }^{5}$ California Oceans Program, The Nature Conservancy, Santa Barbara, California, United States

$12{ }^{6}$ Bren School of Environmental Science \& Management, University of California Santa Barbara,

13 Santa Barbara, California, United States

14

15

16

Corresponding Author:

Lyall Bellquist ${ }^{1,2}$

17410 W. A St., suite 1650, San Diego, California 92101, United States

18 Email address: Lyall.Bellquist@tnc.org

20

21

22

23

24

25

26

27

28

29

30

31

32

33

34

35

36

37

38

39

40

41 
42

43

44

45

46

47

48

49

50

51

52

53

54

55

56

57

58

59

60

61

62

63

64

65

66

67

68

69

70

71

72

73

74

75

76

77

78

79

80

81

82

83

\section{Abstract}

Commercial, recreational, and indigenous fisheries are critical to coastal economies and communities in the United States. For over three decades, the federal government has formally recognized the impact of fishery disasters via federal declarations. Despite these impacts, national syntheses of the dynamics, impacts, and causes of fishery disasters are lacking. We developed a nation-wide Federal Fishery Disaster database using National Oceanic and Atmospheric Administration (NOAA) fishery disaster declarations and fishery revenue data. From 1989-2020, there were 71 federally approved fishery disasters (eleven are pending), which spanned every federal fisheries management region and coastal state in the country. To date, we estimate fishery disasters resulted in \$2B (2019 USD) in Congressional allocations, and an additional, conservative estimate of \$3.2B (2019 USD) in direct revenue loss. Despite this scale of impact, the disaster assistance process is largely ad hoc and lacks sufficient detail to properly assess allocation fairness and benefit. Nonetheless, fishery disasters increased in frequency over time, and the causes of disasters included a broad range of anthropogenic and environmental factors, with a recent shift to disasters now almost exclusively caused by extreme environmental events (e.g., marine heatwaves, hurricanes, and harmful algal blooms). Nationwide, 84.5\% of fishery disasters were either partially or entirely attributed to extreme environmental events. As climate change drives higher rates of such extreme events, and as natural disaster assistance requests reach an all-time high, the federal system for fisheries disaster declaration and mitigation must evolve in order to effectively protect both fisheries sustainability and societal benefit.

\section{Introduction}

Marine fisheries represent an important part of the United States (U.S.) economy, employment, and food security, generating \$244B in annual revenue, providing 1.7M part- and full-time jobs (NOAA, 2020a), and supporting a centuries-long history of community, cultural, and indigenous heritage. While overcapitalization, data limitations, and mismanagement have led to historical fishery declines, more recent fisheries science and management advancements have been achieved nationwide (Methot et al., 2013; NRC, 2014; NOAA, 2016), including improved stock status of U.S. federally managed fisheries and rebuilding of overfished species (NOAA, 2020b). However, climate change and extreme environmental events (e.g., marine heatwaves) are adding significant challenges to an already underfunded and overburdened fisheries management system (Hoegh-Guldberg \& Bruno, 2010; Di Lorenzo \& Mantua, 2016; Wernberg et al., 2016; Free et al., 2019; Belhabib et al., 2018), threatening both national food security and the balance between healthy economies and ecosystems (Ding et al. 2017). The COVID-19 pandemic has also added a new suite of impacts (Bennett et al. 2020), leading to the highest annual number of natural disasters declared in 2020 in the history of the Federal Emergency Management Agency (FEMA, 2020).

Recent improvements in our understanding of linkages between fisheries, ecosystems, climate, communities, and economies indicate that disaster impacts can have rapid and lasting 
84 effects (Hoegh-Guldberg \& Bruno, 2010; Wernberg et al., 2016). When U.S. fisheries are

85 impacted beyond federally designated economic thresholds, the U.S. Secretary of Commerce can

86 formally declare a Federal Fishery Disaster (Upton, 2019), which results in financial

87 compensation for impacted fishing communities. Fishery disaster determinations represent a

88 federal response to anthropogenic and/or environmental impacts that spread throughout entire

89 fisheries supply chains, from the resource itself, to fishing communities, families, and to

90 associated fishing, seafood, clothing/equipment, marine, manufacturing, and hospitality

91 industries (Upton, 2019; Oliver, 2019). Fishery disaster declarations are also largely reactive by

92 design, meaning that when disaster assistance is requested (let alone disbursed), the disaster

93 impacts have already been realized.

94

95

96

97

Fishery disasters are approved on a case-by-case basis by the U.S. Secretary of Commerce under the jurisdiction of sections 312(a) and 315 of the Magnuson-Stevens Fishery Conservation and Management Act (MSA; 16 U.S.C. $\$ 1861(\mathrm{a})$ and $\$ 1864$,), as well as sections 308( $\mathrm{b}$ and d) of the Interjurisdictional Fisheries Act (IFA; 16 U.S.C. §4107). Fishery disaster requests are typically filed by either state governor(s) or elected or duly appointed representative(s) of affected indigenous fishing communities. For a disaster request to be approved, three fundamental criteria must be met: (1) there must be an identified state, federal, or Native American fishery resource disaster associated with either species population decline or loss of fishing infrastructure, (2) it must have an "allowable cause" (Upton, 2019), and (3) there must be economic impact resulting from the disaster. If it is concluded that a fishery disaster occurred, then the economic data are analyzed to determine whether the disaster led to a commercial fishery failure. Commercial fishery failures are declared if revenue losses are greater than $80 \%$ relative to the mean annual revenue over the most recent five-year period (Upton, 2019; Oliver, 2019). Revenue losses of less than 35\% are generally not eligible for assistance, and losses between $35-80 \%$ receive further evaluation. An additional federal designation, a catastrophic regional fishery disaster, may also be declared if the following criteria are met: (1) if either a commercial fishery failure or fishery resource disaster are declared by the U.S. Secretary of Commerce, (2) if the event affects more than one state or fishery managed by a regional council or Interstate Fishery Commission (IFC), and (3) if the event results in economic losses to coastal or fishing communities (Upton, 2019). If a commercial fishery failure is determined, the U.S. Congress may appropriate assistance funds to the impacted states or communities. These groups must then create a spending plan that is reviewed by the National Oceanic and Atmospheric Administration (NOAA) before assistance is administered. Under the MSA, the federal government cannot allocate greater than $75 \%$ of the cost of assistance activities toward individual disaster assistance, with the remaining $25 \%$ typically covered by state or regional entities. The complexity of the process and administrative steps required often result in disbursement of funds occurring years after the disaster occurred (Upton, 2019; Oliver, 2019). Federal Fishery Disaster review and assistance implementation timelines follow a sixstep process: (1) disaster event, (2) request for assistance, (3) analysis and determination, (4) appropriation, (5) allocation, and (6) a grant out for assistance (Fig. 1). Disaster assistance can be structured in numerous ways, generally with fishing communities as the primary intended beneficiaries. Assistance can be appropriated by U.S. Congress and routed through IFCs or individual states, and then allocated directly to fishers and fishing communities through grants, job training, cooperative agreements, contracts, or low-interest loans (Upton, 2019). Assistance can also be administered in a more proactive context to fisheries science or management programs, including data collection, compensated reduction in capacity, or resource restoration 
130 projects. This administrative process can be contentious since federal decision-making may be

131

132

133

134

135

136

137

138

139

140

141

142

143

144

145

146

147

148

149

150

151

152

153

154

155

156

157

158

159

160

161

162

163

164

165

166

167

168

169

170

171

172

173

174

175

unclear, data driving disaster determinations are not publicly reported, impacted individuals or entities may be difficult to identify, and the degree of economic impacts may be difficult to quantify.

The thirty-year history and national scale of fishery disasters in the U.S. indicate a clear need for a nationwide synthesis that can allow fisheries scientists, managers, and policymakers to advance a more adaptive fisheries management approach in a new disaster-specific context. To date, federal fisheries science and management have focused largely on reducing the number of stocks that are overfished or experiencing overfishing. Meanwhile, U.S. Federal Fishery Disasters have been processed on a case-by-case basis with a lack of peer-reviewed science dedicated to comprehensive learning across all disasters. Our aim was to produce a national synthesis that answers how the frequency and causes of disasters have changed since the inception of the assistance program, and to estimate the economic impacts of disasters at both national and regional scales. This will not only inform disaster-related fishery management and policy decisions, but it will expand on our understanding that overfished/overfishing stock metrics, such as the NOAA Fish Stock Sustainability Index (FSSI), should be the primary metric with which we evaluate national fishery management success. To illustrate the scale and trends of disasters and their associated economic impacts, we developed a national and regional database of all Federal Fishery Disasters in the U.S. and synthesized the associated spatial and temporal data reported in U.S. federal disaster records. We used the frequency of disasters and common details across federal disaster requests and approvals to analyze temporal trends and to create a standardized metric for annual and region-specific disaster impacts. We estimated economic impacts based on Congressional allocations for disaster assistance as well as direct fishing revenue loss using NOAA and state-level landings and revenue data. In so doing, we highlight a recent shift in disaster frequency and causes; we discuss inefficiencies in the request, determination, and implementation processes; and we open a discussion for more proactive solutions to managing fishery disasters. This is especially critical when federal disaster assistance requests reached an all-time high (FEMA, 2020), and when climate change impacts are emerging as a significant threat to coastal fisheries, communities, economies, and ecosystems (Hoegh-Guldberg \& Bruno, 2010; Pecl et al, 2017; Lotze et al., 2019).

\section{Materials \& Methods}

We developed a U.S. Federal Fishery Disaster database separated by federal management regions (Fig. 2) using the NOAA Fishery Disaster Assistance online portal produced by the Office of Sustainable Fisheries (NOAA, 2020c). In this portal, fishery disaster determinations were listed with specific disaster information, including (when available) the assistance request letter, federal decision letter, press release, and funding authority. Most disaster records included the affected state(s), year(s), fishery(ies), federal management region, specific area, individual requestor(s), request date and letter, determination status, press release, determination authority and letter, funding authority, cause of the disaster, and appropriation amount. These records, combined with state and federal landings and revenue data, were used to examine trends in disaster frequency and impacts, causes of disasters, federal funding allocation, and direct revenue impacts. We carried out all statistical analyses in the statistical software environment R. All Federal Fishery Disaster data used in these analyses are available at https://www.fisheries.noaa.gov/national/funding-and-financial-services/fishery-disaster-

Peerj reviewing PDF | (2020:11:55726:1:1:NEW 1 Mar 2021) 
176

177

178

179

180

181

182

183

184

185

186

187

188

189

190

191

192

193

194

195

196

197

198

199

200

201

202

203

204

205

206

207

208

209

210

211

212

213

214

215

216

217

218

determinations, and all fishery landings and revenue data are available via the NOAA Fisheries One Stop Shop (FOSS) website (NOAA, 2020d). All code for the analyses are available in the following GitHub repository: https://github.com/vrsaccomanno/federal-fish-disasters.git.

We assessed evidence for change in disaster frequency across the 30-year time series in two ways: 1) we assessed trends in the frequency of disaster determinations per year (each of which may specify multi-year disasters; e.g. a disaster declared in 2002 may specify disaster impact years 1999-2002), and 2) we assessed trends in the number of disasters per year. In both cases, we fit the following Poisson regression generalized linear model (GLM) with a log link, and scaled (Z-scored) year as a fixed continuous effect to model the count of disaster determinations or ongoing disasters per year. Given that the mean and variance for both response variables are approximately equivalent, we feel the assumption of Poisson distributed data is appropriate (we note, however, that findings from a negative binomial instance of the same models were essentially identical). The frequency of disasters will likely vary by management zone (Alaska, Greater Atlantic, Pacific Islands, Southeast, West Coast) in part because different regions are more likely to experience different types of disasters (e.g., hurricanes are not likely to impact the West Coast and Alaska regions). To address the potential for non-independence between zones, we also fit the following Poisson generalized linear mixed models (GLMM) with a fixed continuous effect of year (again, scaled) and random categorical effects of management zones, using the glmer function in the R library lme4 (Bates et al. 2015). Model formulations for both the GLM and GLMM models, including parameter estimates, are provided in Table 1.

Fishery disaster causes were assigned based on information provided in formal federal declarations, request letters, determination letters, press releases, federal fisheries reports, and/or primary literature sources. These causes, such as Harmful Algal Blooms (HABs), hurricanes, warming events, or oil spills, were then condensed into three ordered categories: environmental, combination of environmental and anthropogenic, and anthropogenic. Disasters resulting from hurricanes or HABs were labeled as environmental, but disasters resulting from overfishing or oil spills were labeled as anthropogenic. Because the publicly reported federal disaster declarations did not often include a cited rationale for cause determinations, with many causes labeled arbitrarily as 'natural disaster of unknown causes,' we used peer-reviewed fisheries literature and federal fisheries reports as additional sources for cause classifications. This allowed a more detailed understanding and documentation of the causes of each disaster. For example, causes of West Coast salmon fishery disasters were typically classified as a combination of both environmental (e.g., drought or warming) and anthropogenic (e.g., overfishing, habitat loss, fish passage barriers) factors due to the wide variety of well documented impacts on salmon stocks in each case. Once causes were assigned, disaster records were then separated by cause, year, and management region to highlight not only reasons why disasters are occurring, but also whether the reasons behind them are changing over time. To assess trends in the frequency of these categorical assignment through time, we performed an ordinal logistic regression with the category of each disaster as the response, and year as a fixed continuous effect. As above, we also fit a mixed effects ordinal logistic regression with fixed effect of year and random effects of management zone. We fit the fixed effects model using the polr function in the R library MASS (Ripley et al., 2019), and the mixed effect model using the clmm2 function in the R library ordinal (Christensen, 2019). 
Economic impact associated with each fishery disaster was measured using the federal assistance dollar amount allocated by Congress, as well as estimates of the direct fishing revenue impact. All dollar amounts were converted from nominal to real dollars (2019 USD) using an inflation multiplier from the U.S. Bureau of Labor Statistics CPI inflation Calculator for the year in which the disaster occurred (USBLS, 2020). The federal assistance amount was sourced from the NOAA Fishery Disaster Assistance online portal, although federal disaster number 19 had an allocation amount that was not reported. The request letter for this particular disaster cited economic impacts of \$53.8-94.2M in 2019 USD, and given government policy that the federal share cannot exceed $75 \%$ of a disaster request, this request equates to a maximum federal allocation of approximately $\$ 40.4-70.7 \mathrm{M}$. Therefore, to estimate the total dollar amount allocated by Congress from 1994-2020, we combined the federal allocation amounts from the 65 known cases reported on the portal, the overall amount that was Congressionally approved for all disasters in aggregate in 2019 and 2020, and the estimate from the single unknown case (disaster number 19, Table S1).

To estimate the direct revenue impact associated with each fishery disaster - defined as revenue loss associated only with changes in landings and not throughout the supply chain - we evaluated each determination in accordance with NOAA Fisheries policy guidance on economic thresholds required for a successful determination (Denit, 2018); the difference in revenue of the impacted fishery during the disaster year(s) relative to the previous five-year average was calculated to produce revenue loss estimates. While revenue loss data were not explicitly reported in the federal disaster records, we were able to collect landings and nominal revenue data for each disaster using the NOAA Fisheries One-Stop Shop (FOSS) online database in most cases (NOAA, 2020d). When an approved disaster required finer spatial resolution landings and revenue data (e.g., if the fishery/area affected was smaller than the state-level scale), state landings sources were used to isolate regional-level data when possible. There were several disasters where landings and revenue data for the appropriate spatial scale (e.g., a regional bay) and/or management entity (e.g., tribal) were not obtainable; in these instances, the next best viable data source was used when available and the revenue impact estimate of the disaster was assigned a confidence level (i.e., low, medium, high) based on how well the landings and revenue data reflected the spatial scale of - and management entity impacted by - the disaster (Table S1). There were eight disasters in which viable data were completely unobtainable; these disasters are demarcated with "N/A" in the Net Revenue Change column in Table S1.

Direct revenue data were obtainable for 63 of the 71 approved fishery disasters. Changes in revenue in multi-year disasters - as reported on NOAA's online portal (NOAA, 2020e) - were evaluated on an annual basis relative to the corresponding previous five-year average; while direct revenue data were obtainable for 63 disasters, calculating revenue loss for each disaster year resulted in more than 63 disaster years due to the handful of multi-year disasters $(n=79)$. Non-parametric bootstrapping techniques were used to estimate the sampling distribution of the median direct revenue impact and associated measures of uncertainty because the obtained revenue impact estimates were non-normally distributed (a Shapiro-Wilk test showed a 
259

260

261

262

263

264

265

266

267

268

269

270

271

272

273

274

275

276

277

278

279

280

281

282

283

284

285

286

287

288

289

290

291

292

293

294

295

296

297

298

299

300

301

302

303

significant departure form normality, $\mathrm{W}=0.71, \mathrm{p}<0.001)$. For each sample statistic, 100,000 replications were performed using the "Boot" package in R programming language (Davison \& Hinkley, 1997; Canty \& Ripley, 2019; R Core Team. 2019).

\section{Results}

There were 96 Federal Fishery Disaster assistance requests filed in the U.S. since 1994 (as of Oct 2020), spanning the impact period from 1989-2019, during which time 71 disasters were federally approved (Table S1). Congressional allocations and direct revenue loss data were available for 65 and 63 of the 71 approved disasters, respectively. The available data allowed estimates of the missing Congressional allocation values (see Supplementary Methods) and subsequent analyses of economic impact. Federal disaster records also allowed analyses of disaster frequency and causes of disasters.

\section{Economic impact}

For the purposes of this study, all economic estimates are reflected in 2019 USD, with eleven 2020 assistance requests still pending. The total amount allocated by Congress throughout the entire federal disaster assistance program from 1994-2020 was over \$1.99B (Table 2). This does not include six approved disasters with unreported federal assistance amounts, and it also does not include amounts that are still being determined for five disasters that were approved in 2019, as well as eleven disaster requests from 2019 and 2020 that have not yet been approved. However, a total of $\$ 165 \mathrm{M}$ was Congressionally appropriated for the 2019 fiscal year. In 2020, U.S. Congress used the Coronavirus Aid, Relief, and Economic Security Act (CARES Act: https://www.fisheries.noaa.gov/national/noaa-fisheries-coronavirus-covid-19-update) to approve the allocation of an additional $\$ 300 \mathrm{M}$ for fisheries as a result of the ongoing COVID-19 pandemic.

Total assistance allocations were highly variable across space and time (i.e., no apparent trend), and ranged from $\$ 0-\$ 300 \mathrm{M}$ annually (mean of $\$ 73.8 \mathrm{M} \pm \$ 96.1 \mathrm{M} \mathrm{SD}$ ). The Southeast Region (www.fisheries.noaa.gov/regions) obtained the most assistance since the inception of the program $(\$ 574 \mathrm{M}, 36.4 \%$ of overall determined funding), followed by the West Coast $(\$ 460 \mathrm{M}$, $29.2 \%)$, Alaska (\$332M, 21.0\%), Greater Atlantic $(\$ 211 \mathrm{M}, 13.4 \%)$, and Pacific Islands $(\$ 1 \mathrm{M}$, $0.1 \%$ ). Overall, the entire western U.S. (Alaska, West Coast, and Pacific Islands combined) accounted for $50.3 \%$ of all approved U.S. disaster allocations (excluding pending disasters), while the Southeast and Greater Atlantic Regions accounted for 49.7\% of allocations (Table 2).

We generated direct revenue loss estimates - defined as revenue loss associated only with changes in landings - for 63 of the 71 approved fishery disasters, which amounted to over $\$ 3.2 \mathrm{~B}$ in revenue loss from 1994-2019, with additional significant revenue losses anticipated in 2020 due to the ongoing COVID-19 pandemic. These estimates were non-normally distributed, motivating the use of non-parametric statistical techniques. The median percent change in revenue during a disaster relative to the mean annual revenue over the preceding five-year period was -38.3 (IQR range $=-70.4--1.3$ ) across the 63 disasters for which data were attainable (Table S1). We also found that 12 of the 63 disasters showed a net increase in revenue in the year(s) of the disaster reported on the online portal. Omitting these 12 cases (to reflect total revenue losses that occurred) results in a median percent change in revenue of -60.6 (IQR range $=-74.1-24.8)$. The median revenue loss in a disaster year was $-\$ 3.5 \mathrm{M}(\mathrm{n}=79)$, with a 
304 bootstrapped 95\% confidence interval of $[-\$ 5.6 \mathrm{M}-\$ 4.8 \mathrm{M}](\mathrm{n}=100,000$ bootstrap samples)

305 across the 63 disasters for which data were attainable. Omitting the 12 cases where revenue

306 increased results in a median revenue loss in a disaster year of $-\$ 11.6 \mathrm{M}(\mathrm{n}=62)$, with a

307 bootstrapped $95 \%$ confidence interval of $[-\$ 18.7 \mathrm{M}--\$ 7.6 \mathrm{M}](\mathrm{n}=100,000$ bootstrap samples).

308 The Alaska Region accounted for $66.2 \%$ of the revenue impact overall, followed by the West

309 Coast Region (18.1\%), Southeast Region (10.7\%), Greater Atlantic (5.1\%), and Pacific Islands

$310(<0.01 \%)$ (see GitHub repository for code specific to revenue loss estimates:

311 https://github.com/vrsaccomanno/federal-fish-disasters.git).

312

313

314

315

316

317

318

319

320

321

322

323

324

325

326

327

328

329

330

331

332

333

334

335

336

337

338

339

\section{Disaster trends}

All statistical models (GitHub repository: https://github.com/vrsaccomanno/federal-fishdisasters.git) strongly indicate that disasters are increasing over time (i.e. that the number of disaster declarations and number of disasters per year have both increased; Table 1), even with eleven disasters during the 2017-2020 period that are still pending review (Fig. 3). The mixed effects models converged but with much larger AIC scores than counterpart fixed effects only models, indicating a poor model fit (Table 1). Moreover, the similarity in the estimated fixed year effect coefficients in both the mixed and fixed effects models (Table 1) suggests the mixed effects formulation is inconsequential to our findings.

It is possible that auto-correlation could manifest in the generative processes underlying our time-ordered data. That is, the underlying causes of disasters such as climate driven storm events or mis-management may carry momentum through time. Such a lack of independence between data points would violate the assumptions of the statistical methods we applied. However, we found no evidence of this based on an analysis of autocovariance in the residuals of the linear model regressing the number of disasters across years. In fact, the correlation at lag 1 (adjacent residuals) was $\sim 0$, and no lag regardless of size had a correlation of $>|0 .-2|$ (https://github.com/vrsaccomanno/federal-fish-disasters.git). We are therefore confident that the statistical findings from our GLM models are robust.

Fishery disasters impacted every federal fisheries management region, and every coastal state in the U.S., as well as the U.S. Virgin Islands, Puerto Rico, and American Samoa. Impacts were largely to commercial and recreational groundfish, commercial nearshore invertebrates, and commercial and Native American salmon fisheries, although several assistance requests and determinations simply stated only that "multiple fisheries" were impacted. Regional trends in disaster frequency showed a distinct shift from disasters across all regions between 1994-2015 to disasters occurring almost entirely in the West Coast and Southeast management regions from 2017-2019. The West Coast management region had the highest share of approved disasters (28/71), followed by the Southeast (18/71), Alaska (14/71), Greater Atlantic (10/41), and Pacific Islands (1/71) regions. Overall, the entire western U.S. (including one approved disaster in the Pacific Islands) accounted for $60.6 \%$ of all approved U.S. disasters, while the Gulf Coast and east coast accounted for $39.4 \%$ of approved disasters.

\section{Disaster causes}

Since the 1990s, the predominant cause of fisheries disasters has shifted from anthropogenic to environmental in nature, with extreme environmental events reflecting $95.3 \%$ of the revenue loss during the most recent years (2014-2019), increasing from 38.5\% during the first five years (1994-1998). Disaster causes were aggregated into three condensed categories: anthropogenic, environmental, or a combination of both. Marine heatwaves accounted for the 
350

351

352

353

354

355

356

357

358

359

360

361

362

363

364

365

366

367

368

369

370

371

372

373

374

375

376

377

378

379

380

381

382

383

384

385

386

387

388

389

390

391

392

393

394

395

most disasters overall, followed by hurricanes, overfishing, low returns (multiple Pacific salmon species), and HABs. Disasters caused by "low returns" in salmon fisheries were typically due to a combination of anthropogenic and environmental factors. Both the fixed and random effects logistic regression models performed similarly in terms of AIC scores (Table 1), with both showing significant time trends in the cause of disasters (Fig. 4). Regionally, marine heatwaves and HABs were often attributed to disasters in the both the West Coast and the New England / Greater Atlantic Regions, while hurricanes represented the primary cause of disasters in the Southeast Region. The majority of disasters with Congressional allocations were attributed to environmental causes ( $\$ 894 \mathrm{M}, 56.6 \%$ of total determined allocations), followed by a combination of both $(\$ 431 \mathrm{M}, 27.3 \%)$, and lastly, anthropogenic causes $(\$ 254 \mathrm{M}, 16.1 \%$; Table 2). There were no apparent trends in Congressional allocations by cause or region, although extreme environmental events were either partially or fully attributed to $84 \%$ of all Congressional allocations. In terms of revenue loss to fisheries, anthropogenic causes led to $\$ 1.8 \mathrm{~B}(56.4 \%)$ in losses, although this was almost entirely driven by overfishing in the Alaska snow crab fishery (four federally approved disasters in total). Environmental causes resulted in an additional $\$ 900 \mathrm{M}(27.9 \%)$ in losses, and $\$ 505 \mathrm{M}(15.7 \%)$ in losses were attributed to a combination of anthropogenic and environmental causes (Table 3 ).

\section{Federal timelines}

The average time to fully process a disaster declaration was approximately 2.1 years ( \pm 1.4 years SD), with a maximum total process time of six years, and one disaster request from 2005 that remains undetermined. The time period from the disaster occurrence to the formal assistance request filing averaged 6.4 months $( \pm 12.0$ months SD), with $66.2 \%$ of requests being filed within 1 year after the disaster, and $87.7 \%$ filed within 2 years after the disaster. Once the request was filed, determination time (time between steps 2 and 3 of the 6-step process) lasted as long as 4.0 years (mean of $8.3 \pm 8.7$ months SD). One disaster approval occurred 92 days before the request was formally filed (disaster number 29: Hurricane Katrina).

\section{Discussion}

Federal Fisheries Disasters have generated large, yet remarkably variable revenue impacts throughout the U.S. during the last three decades, and the frequency of disasters is increasing over time. In turn, the U.S. government has spent billions of dollars to mitigate these impacts. In the early days of fishery disaster determinations, these impacts were largely due to mixed factors and relatively poor fisheries management. Fortunately, such direct anthropogenic causes of disasters appear to be on the wane as fisheries management improves (e.g., Marshall et al. 2019, Hilborn et al. 2020, NOAA, 2020b). However, environmentally-driven fishery disasters are clearly on the rise, fueled by extreme environmental events that occur as symptoms of a changing climate (Cheung \& Frölicher, 2020; Jacox et al., 2020; Laufkötter, Frölicher, \& Zscheischler, 2020). For example, the U.S. west coast marine heat wave event of 2013-2016 (e.g., the warm 'blob') produced a broad range of coastwide impacts (Cavole et al., 2016), including several approved Federal Fishery Disasters (e.g., Holland \& Leonard, 2020). In total, these marine heatwaves were the dominant environmental cause of Federal Fishery Disasters nationwide in the 30-year time series, followed by hurricanes and HABs, but almost all marine heatwave events occurred only in the recent 2013-2020 period. This recent emergence of marine heatwaves, which occurred on both the east and west coasts of the U.S., thus accounted for much of the increasing trend in fishery disasters. Taken together, our findings suggest that not only are 
396 fisheries disasters on the rise, but the linkage between climate change, marine heatwaves

397 (Frölicher, Fischer, \& Gruber 2018; Oliver et al., 2018; Holbrook et al., 2019), and now Federal

398 Fishery Disasters is becoming increasingly clear, and the causes of fishery disasters are shifting

399 from those with conventional management solutions, to those that require more pro-active and

400 climate-ready policies (Pinsky \& Mantua 2014). Similar temporal shifts in impact causes were

401 documented for animal mass mortality events, which included both marine and terrestrial species

402 (Fey et al. 2015). This shift toward increased impacts due extreme environmental events is also

403 consistent with numerous studies documenting unprecedented and accelerating oceanographic,

404 ecosystem, and fisheries changes during the same time period (Bond et al., 2015; Peterson,

405 Robert, \& Bond, 2015; Ritzman et al., 2018; Thompson et al., 2018; Arafeh-Dalmau et al., 2019;

406 Piatt et al., 2020; Santora et al. 2020).

407 Despite the multi-billion dollar economic impacts, we are likely underestimating the true

408 magnitude of the economic effects of Federal Fishery Disasters. First, our economic analyses

409 only include estimates for 63 of the 71 approved fishery disasters due to data limitations, and

410 there are still eleven pending disaster requests that were also not included in the analysis.

411 Second, our analyses represent fisheries that were formally included in federal assistance

412 requests, but there may be impacted fisheries/communities that never applied for assistance.

413 Third, our revenue impact estimates only included losses during the disaster year(s) as reported

414 on the online portal, not potential losses in subsequent years due to delayed impacts. Fourth, our

415 impact analyses were based on the NOAA disaster determination model that uses direct

416 commercial fishing revenue as the primary impact metric, but indirect economic losses across

417 supply chains are undoubtedly larger (Holland \& Leonard, 2020). In addition, direct and indirect

418 revenue contributions from recreational fisheries, which generate $\$ 68 \mathrm{~B}$ in national annual sales

419 (NOAA, 2018), were generally not included in our economic impact analyses due to data

420 limitations. Fifth, because disaster requests and approvals often take years to process and

421 publicly report, there will likely be disaster requests added to the most recent 2018-2020 period,

422 meaning that our results may represent a conservative estimate of increasing trends over time and

423 economic impacts during these recent years. Finally, our study only focused on economic impact

424 estimates, but fishery disasters also reflect impacted ecosystems, communities, and cultures that

425 were not the focus of our analyses (e.g., Smith \& Gilden 2000). These represent critical

426 components of the overall impact from fishery disasters that should be a focus of future science

427 and policy engagements.

428 The magnitude of economic impacts of fishery disasters is clearly a problem, but the lack 429 of standardized reporting with sufficient detail in disaster requests and determinations creates 430 significant challenges for implementing solutions. For example, the median revenue loss across 431 all approved disasters (38.3\% loss) was notably less than the $80 \%$ threshold that triggers federal 432 determination of a commercial fishery failure, and is just above the $35 \%$ threshold that allows 433 further review according to federal guidelines. We also identified 12 cases of federally approved 434 disasters in which fishery-specific direct revenue actually increased during the disaster year 435 relative to the previous 5-year average, a surprising finding given that an increase in revenue in a 436 disaster year does not meet NOAA Fisheries policy guidance on economic thresholds required 437 for a successful determination (we omitted these cases from our impact estimates under the 438 rationale that gains in one fishery do not erase losses sustained in another). Our conservative 439 estimates of economic impacts may not be capturing the full scale of impact, but the consistency 440 in the economic metric used between our study and the federal determination process suggests a 441 need for improved economic data collection and federal reporting. Improved reporting would 
442 also provide critically needed clarification about specifically which fisheries are impacted. For 443 example, fishery disasters ranged in spatial scale from individual rivers to multiple states; they 444 might impact only one Native American community or several; and they might affect only one 445 fishery or virtually every fishery in a state or region. Enumerating disaster impact by specific 446 fisheries is thus problematic because information about which species, fisheries, and 447 communities were affected was not always provided in federal disaster assistance requests and 448 determinations. These details could facilitate improved estimations of impact, more transparency

449

450

451

452

453

454

455

456

457

458

459

460

461

462

463

464

465

466

467

468

469

470

471

472

473

474

475

476

477

478

479

480

481

482

483

484

485

486

487 when and where the Secretary of Commerce determines there are special circumstances that may justify using a lower threshold of percent revenue loss in disaster determinations, and a more streamlined and transparent process for estimating and allocating assistance to the most heavily impacted fisheries and fishing communities.

Problems also exist with assistance processing lags and opaque determination process. Across all Federal Fishery Disaster declarations, total federal process duration (Fig. 1, duration between steps one and six) averaged 2.1 years, ranging from zero to six years after the disaster event. Such delayed response times are likely due both to the complex determination and allocation process, and the burden of increasing disaster assistance request rates. The administrative process can also be contentious because federal assistance timelines can significantly lag impact events, federal decision-making is often unclear (or undocumented), impacted individuals or entities may be difficult to identify, and the degree of economic impacts may be difficult to quantify (Upton, 2019). A more detailed accounting of determinations could address these issues, and reveal aspects of the determination process that are leading to such highly variable response times.

The federal response to the growing impacts of fishery disasters clearly needs reform, but the lack of standardized reporting in Federal Fishery Disaster requests and determinations makes identifying solutions difficult. Our finding that many of the published determinations failed to list the specific commercial fishery(ies) used to make the determination is problematic. While disasters ranged in scale from individual fish stocks and fisheries to multiple states and fishing communities, the details provided in determination documents do not reflect the complexity of disaster impacts. Transparent, detailed, and mechanistic descriptions of economic impact determinations are necessary for the Secretary of Commerce to determine if there are special circumstances that may justify using a lower threshold of percent revenue loss in Federal Fishery Disaster determinations. To achieve this, public reporting of a full economic impact assessment in each fishery would undoubtedly cause prohibitive slowing of the disaster assistance process, but publicly reporting the data that are already behind each disaster determination would achieve a greater level of transparency and impact detail while adding little to the process and timeline. In addition, there is need for a more streamlined, fair, and transparent process for allocating assistance (Oliver, 2019; Upton, 2019). While compensation of fishing communities is the ultimate goal of disaster assistance, we found that approximately $40 \%$ of federal determinations failed to identify the specific fishery(ies) impacted by the disaster, making any future efforts to accountability in assistance allocation difficult, if not impossible.

This study represents a national-scale view of fishery disasters, a problem that has worsened over time, and has cascading socioeconomic impacts to society. This study also highlights a clear need for consideration of ecosystem and cultural impacts of fishery disasters that were not the focus of this study. For example, Native American fisheries represent a far more extensive history of coastal harvest and culture than commercial or recreational fisheries, illustrating the intimate connection possible between nature and people that span millennia.

Peer) reviewing PDF | (2020:11:55726:1:1:NEW 1 Mar 2021) 
488 However, in three decades, 29 federally approved (and four pending) disasters have impacted 489 salmon fisheries in the Pacific northwest (Smith \& Gilden, 2000). Over half of these requests 490 came from Native American communities that have been intimately connected with salmon

491

492

493

494

495

496

497

498

499

500

501

502

503

504

505

506

507

508

509

510

511

512

513

514

515

516

517

518

519

520

521

522

523

524

525

526

527

528

529

530

531 populations for generations, yet limited syntheses of disaster impacts to indigenous communities are available. Knowledge of the disruptions in such cultural relationships should be a necessary part of efforts to mitigate the totality of fishery disaster impacts, yet such considerations are not currently part of the Federal Fishery Disaster determination process.

As currently structured, the legal framework for declaring Federal Fishery Disasters can depend on a range of economic impact metrics that typically go unreported in disaster determinations, but Congressional appropriations depend on demonstrating a direct loss of revenue to commercial fisheries. However, there is no question that the broader market and nonmarket value of fisheries losses grossly outweigh the direct revenue loss (Holland \& Leonard, 2020; Seung, 2017). These additional impacts encapsulate fisheries supply chains, cultural values, and non-commercial impacts. The fact that the existing legal mechanisms for fishery disaster assistance hinge largely on direct revenue loss may explain why many declared Federal Fishery Disasters fail to meet the defined economic loss thresholds (e.g., in some disasters, revenue actually increased); it is likely lawmakers are making a good-faith effort to account for the true breadth of economic and societal loss stemming from disaster. However, the lack of a codified mechanism for doing so contributes to inaccurate accounting of financial assistance.

\section{Conclusions}

As disaster impacts to fishing communities worsen via increased disaster frequencies, federal response times to mitigate these impacts continue to lag by years in most cases (Upton, 2019). Developing proactive, rather than reactive, mitigation strategies may partially address this problem. Recent shifts in the causes of fishery disasters toward extreme environmental events suggest a need to explore incentive structures for linking disaster assistance with proactive climate-ready fisheries management (Pinsky \& Mantua, 2014). Regional fishery disaster vulnerability assessments (Badjeck et al., 2013), ecosystem-based fishery management approaches (Holsman et al., 2020), responsive harvest control rules (Kritzer et al. 2019), and accounting for climate-related shifts in fisheries productivity/distributions (Free et al., 2020) may all be useful in guiding science and management efforts toward this end. Industry insurance mechanisms, such as those trialed in west coast salmon fisheries, might also mitigate future extreme event scenarios by providing timely assistance to those in greatest need, as well as incentivized support for climate-ready fisheries management goals (Mumford et al., 2009).

There has never been a better time to identify and implement more effective government response to disasters. The COVID-19 pandemic has added a new layer of impacts across virtually every sector of the global economy, including fisheries (Bennett et al., 2020). By September 2020, the U.S. had already reached a record annual number of natural disasters declared (56\% of which were linked to COVID-19 at the time of submission) by FEMA in the history of U.S. natural disaster declarations (1953-2020). In the fisheries sector, the seafood industry landscape has been severely impacted, with entire fleets tied to the docks, and fisheries market closures occurring around the world (Bennett et al., 2020). The pandemic has led to an unprecedented need for federal assistance across a significant portion of the U.S. economy, including $\$ 300 \mathrm{M}$ approved for fishery disasters in 2020 as part of the Coronavirus Aid, Relief, 
532 and Economic Security Act (CARES Act). The scale of need for federal assistance this year 533 highlights the critical importance of preventing and mitigating disasters with climate-ready 534 management models, maximizing efficiency in the federal assistance process, and increasing the 535 impact of every federal dollar spent during these extreme and uncertain circumstances.

536

537

538

539

540

541

542

543

544

545

546

547

548

549

550

551

552

553

554

555

556

557

558

559

560

561

562

563

564

565

566

567

568

569

570

571

572

573

574

\section{Acknowledgements}

We sincerely thank Alexis Jackson, Jenn Humberstone, Tom Dempsey, Kate Kauer, Aliya Rubinstein, Norah Eddy, Frank Hurd, Chris Free, Bradley Franklin, and Darcy Bradley for draft reviews, edits, and/or project advice. We also thank NOAA Fisheries staff members for providing clarification about the fishery disaster assistance process, as well as NOAA-led efforts to develop new disaster policies and solutions. We also thank the journal editor and anonymous reviewers who contributed valuable insight toward improving this manuscript.

\section{References}

Arafeh-Dalmau, N., Montaño-Moctezuma, G., Martinez, J. A., Beas-Luna, R., Schoeman, D. S., \& Torres-Moye, G. (2019). Extreme Marine Heatwaves alter kelp forest community near its equatorward distribution limit. Frontiers in Marine Science, 6, 499.

Badjeck, M.-C., Perry, A., Renn, S., Brown, D. \& Poulain, F. (2013). The vulnerability of fishing-dependent economies to disasters. FAO Fisheries and Aquaculture Circular, No. 1081. Rome, FAO. 19 pp.

Bates, D., Maechler, M., Bolker, B., Walker, S., Christensen, R.H.B., Singmann, H., Dai, B., Grothendieck, G., Green, P. and Bolker, M.B., 2015. Package 'lme4'. Convergence, 12(1), p.2.

Belhabib, D., Dridi, R., Padilla, A., Ang, M. and Le Billon, P. (2018). Impacts of anthropogenic and natural "extreme events" on global fisheries. Fish and Fisheries, 19, 1092-1109.

Bennett, N.J., Finkbeiner, E.M., Ban, N.C., Belhabib, D., Jupiter, S.D., Kittinger, J.N., Mangubhai, S., Scholtens, J., Gill, D. and Christie, P. (2020). The COVID-19 pandemic, smallscale fisheries and coastal fishing communities. Coastal Management, 48, 336-347.

DOI: $10.1080 / 08920753.2020 .1766937$

Bond, N.A., Cronin, M.F., Freeland, H. and Mantua, N. (2015). Causes and impacts of the 2014 warm anomaly in the NE Pacific. Geophysical Research Letters, 42, 3414-3420.

Canty, A. and Ripley, B. (2019). Boot: Bootstrap R (S-Plus) Functions. R package version 1.324.

Peer] reviewing PDF | (2020:11:55726:1:1:NEW 1 Mar 2021) 
575 Cavole, L.M., Demko, A.M., Diner, R.E., Giddings, A., Koester, I., Pagniello, C.M., Paulsen,

576 M.L., Ramirez-Valdez, A., Schwenck, S.M., Yen, N.K. and Zill, M.E. (2016). Biological

577 impacts of the 2013-2015 warm-water anomaly in the Northeast Pacific: Winners, losers, and

578 the future. Oceanography, 29, 273-285.

579

580

581

582

583

584

585

586

587

588

589

590

591

592

593

594

595

596

597

598

599

600

601

602

603

604

605

606

607

608

609

610

611

612

613

614

615

616

617

618

619

Cheung, W.W. and Frölicher, T.L. (2020). Marine heatwaves exacerbate climate change impacts for fisheries in the northeast Pacific. Scientific reports, 10, 1-10.

Christensen, R. H. B. (2019). Ordinal—regression models for ordinal data. R package version, 2019.12-10.

Davison, A, and Hinkley, D.V. (1997). Bootstrap methods and their applications. Cambridge University Press, Cambridge. ISBN

Denit, K. (2018). National Marine Fisheries Service Policy 01-122. Policy on disaster assistance under the Magnuson-Stevens Act 3129(A) and 315, and Interjurisdictional Fisheries Act 308(B) and 308(D). National Oceanic and Atmospheric Administration, U.S. Department of Commerce.

Di Lorenzo, E. and Mantua, N. (2016). Multi-year persistence of the 2014/15 North Pacific marine heatwave. Nature Climate Change, 6, 1042-1047.

Ding, Q., Chen, X., Hilborn, R. and Chen, Y. (2017). Vulnerability to impacts of climate change on marine fisheries and food security. Marine Policy, 83, 55-61.

Federal Emergency Management Agency (FEMA). (2020). http://www.fema.gov/disasters

Fey, S. B., Siepielski, A. M., Nusslé, S., Cervantes-Yoshida, K., Hwan, J. L., Huber, E. R., Fey, M. J., Catenazzi, A., Carlson, S. M. (2015) Recent shifts in the occurrence, cause, and magnitude of animal mass mortality events. Proceedings of the National Academy of Sciences, 112, 10831088.

Free, C.M., Thorson, J.T., Pinsky, M.L., Oken, K.L., Wiedenmann, J. and Jensen, O.P. (2019). Impacts of historical warming on marine fisheries production. Science, 363, 979-983.

Free, C.M., Mangin, T., Molinos, J.G., Ojea, E., Burden, M., Costello, C. and Gaines, S.D. (2020). Realistic fisheries management reforms could mitigate the impacts of climate change in most countries. Plos one, 15, p.e0224347.

Frölicher, T.L., Fischer, E.M. and Gruber, N. (2018). Marine heatwaves under global warming. Nature, 7718, 360-364.

Hilborn, R., Amoroso, R.O., Anderson, C.M., Baum, J.K., Branch, T.A., Costello, C., De Moor, C.L., Faraj, A., Hively, D., Jensen, O.P., Kurota, H., Little, L.R., Mace, P., McClanahan, T., Melnychuk, M.C., Minto, C., Chato Osio, G., Parma, A.M., Pons, M., Segurado, S., Szuwalski, C.S., Wilson, J.R., and Ye, Y. (2020). Effective fisheries management instrumental in improving 620 fish stock status. Proceedings of the National Academy of Sciences, 117, 2218-2224. 
621

622

623

624

625

626

627

628

629

630

631

632

633

634

635

636

637

638

639

640

641

642

643

644

645

646

647

648

649

650

651

652

653

654

655

656

657

658

659

660

661

662

663

664

665

Hoegh-Guldberg, O. and Bruno, J.F. (2010). The impact of climate change on the world's marine ecosystems. Science, 328, 1523-1528.

Holbrook, N.J., Scannell, H.A., Gupta, A.S., Benthuysen, J.A., Feng, M., Oliver, E.C., Alexander, L.V., Burrows, M.T., Donat, M.G., Hobday, A.J. and Moore, P.J. (2019). A global assessment of marine heatwaves and their drivers. Nature Communications, 10, 1-13.

Holland, D.S. and Leonard, J. (2020). Is a delay a disaster? economic impacts of the delay of the California dungeness crab fishery due to a harmful algal bloom. Harmful Algae, 98, 101904.

Holsman, K.K., Haynie, A.C., Hollowed, A.B., Reum, J.C.P., Aydin, K., Hermann, A.J., Cheng, W., Faig, A., Ianelli, J.N., Kearney, K.A. and Punt, A.E. (2020). Ecosystem-based fisheries management forestalls climate-driven collapse. Nature Communications, 11(1), 1-10.

Jacox, M.G., Alexander, M.A., Bograd, S.J. and Scott, J.D. (2020). Thermal displacement by marine heatwaves. Nature, 584, 82-86.

Kritzer, J.P., Costello, C., Mangin, T. and Smith, S.L. (2019). Responsive harvest control rules provide inherent resilience to adverse effects of climate change and scientific uncertainty. ICES Journal of Marine Science, 76, 1424-1435.

Laufkötter, C., T. L. Frölicher, and J. Zscheischler. (2020) High-impact marine heatwaves attributable to human-induced global warming. Science, 369, 1621-1625.

Lotze, H.K., Tittensor, D.P., Bryndum-Buchholz, A., Eddy, T.D., Cheung, W.W., Galbraith, E.D., Barange, M., Barrier, N., Bianchi, D., Blanchard, J.L. and Bopp, L. (2019). Global ensemble projections reveal trophic amplification of ocean biomass declines with climate change. Proceedings of the National Academy of Sciences, 116, 12907-12912.

Marshall, K.N., Koehn, L.E., Levin, P.S., Essington, T.E. and Jensen, O.P. (2019). Inclusion of ecosystem information in US fish stock assessments suggests progress toward ecosystem-based fisheries management. ICES Journal of Marine Science, 76, 1-9.

Methot Jr, R.D., Tromble, G.R., Lambert, D.M. and K.E. Greene. (2013). Implementing a science-based system for preventing overfishing and guiding sustainable fisheries in the United States. ICES Journal of Marine Science, 71, 183-194.

Mumford, J.D., Leach, A.W., Levontin, P. and Kell, L.T. (2009). Insurance mechanisms to mediate economic risks in marine fisheries, ICES Journal of Marine Science, 66, 950-959.

National Oceanic and Atmospheric Administration, NOAA. (2016). NOAA fisheries ecosystembased fisheries management road map. National Marine Fisheries Service Instruction 01-120-01, Department of Commerce: Silver Spring.

Peer) reviewing PDF | (2020:11:55726:1:1:NEW 1 Mar 2021) 
666 National Oceanic and Atmospheric Administration, NOAA. (2020a). Fisheries Economics of the 667 United States, 2018. U.S. Dept. of Commerce, NOAA Tech. Memo. NMFS-F/SPO-187, 243 p.

668

669

670

671

672

673

674

675

676

677

678

679

680

681

682

683

684

685

686

687

688

689

690

691

692

693

694

695

696

697

698

699

700

701

702

703

704

705

706

707

708

709

710

National Oceanic and Atmospheric Administration, NOAA. (2020b). Office of Sustainable Fisheries, "2019 Report to Congress on the Status of U.S. Fisheries" https://www.fisheries.noaa.gov/national/sustainable-fisheries/status-stocks-2019

National Oceanic and Atmospheric Administration, NOAA. (2020c). National Oceanic and Atmospheric Administration. NOAA Fisheries. 2020. Fishery disaster Assistance Program. https://www.fisheries.noaa.gov/national/funding-and-financial-services/fishery-disasterassistance

National Oceanic and Atmospheric Administration, NOAA. (2020d). https://foss.nmfs.noaa.gov/apexfoss/f?p=215:200:15102706929889::.::

National Oceanic and Atmospheric Administration, NOAA. (2020e). Fishery disaster determinations. https://www.fisheries.noaa.gov/national/funding-and-financial-services/fisherydisaster-determinations

National Research Council. (2014). Evaluating the effectiveness of fish stock rebuilding plans in the United States. National Academies Press, Washington, D.C.

Oliver, C. (2019). Testimony of Chris Oliver, Assistant Administrator for Fisheries, National Marine Fisheries Service, on fishery disasters before the U.S. Senate Commission on Commerce, Science, and Transportation. National Marine Fisheries Service, U.S. Department of Commerce. https://www.commerce.senate.gov/services/files/0F9421E1-2929-4FBE-A8C7-84A2CC440E63

Oliver, E.C.J., Donat, M.G., Burrows, M.T., Moore, P.J., Smale, D.A., Alexander, L.V., Benthuysen, J.A., Feng, M., Sen Gupta, A., Hobday, A.J., Holbrook, N.J., Perkins-Kirkpatrick, S.E., Scannell, H.A., Straub, S.C., Wernberg, T. (2018). Longer and more frequent marine heatwaves over the past century. Nature Communications, 9, 1-12.

Pecl, G.T., Araújo, M.B., Bell, J.D., Blanchard, J., Bonebrake, T.C., Chen, I.C., Clark, T.D., Colwell, R.K., Danielsen, F., Evengård, B. and Falconi, L. (2017). Biodiversity redistribution under climate change: Impacts on ecosystems and human well-being. Science, 355, DOI 10.1126/science.aai9214

Peterson, W., Robert, M. and Bond, N. (2015). The warm blob continues to dominate the ecosystem of the northern California current. PICES Press, 23, 44-46.

Piatt, J.F., Parrish, J.K., Renner, H.M., Schoen, S.K., Jones, T.T., Arimitsu, M.L., Kuletz, K.J., Bodenstein, B., García-Reyes, M., Duerr, R.S. and Corcoran, R.M. (2020). Extreme mortality and reproductive failure of common murres resulting from the northeast Pacific marine heatwave of 2014-2016. PloS one, 15, p.e0226087.

Peer) reviewing PDF | (2020:11:55726:1:1:NEW 1 Mar 2021) 
711 Pinsky, M.L., and N.J. Mantua. (2014). Emerging adaptation approaches for climate-ready

712 fisheries management. Oceanography, 27:146-159.

713

714 R Core Team. 2019. R: A language and environment for statistical computing. R Foundation for

715 Statistical Computing, Vienna, Austria. http://www.R-project.org/

716

717 Ripley, B., Venables, B., Bates, D. M., Hornik, K., Gebhardt, A., Firth, D., \& Ripley, M. B.

718 (2019). Package 'mass'. R package version, 7.3-51.5.

719

720

721

722

723

724

725

726

727

728

729

730

731

732

733

734

735

Ritzman, J., Brodbeck, A., Brostrom, S., McGrew, S., Dreyer, S., Klinger, T. and Moore, S.K. (2018). Economic and sociocultural impacts of fisheries closures in two fishing-dependent communities following the massive 2015 US West Coast harmful algal bloom. Harmful algae, $80,35-45$.

Santora, J.A., Mantua, N.J., Schroeder, I.D., Field, J.C., Hazen, E.L., Bograd, S.J., Sydeman, W.J., Wells, B.K., Calambokidis, J., Saez, L. and Lawson, D. (2020). Habitat compression and ecosystem shifts as potential links between marine heatwave and record whale entanglements. Nature Communications, 11, 536. https://doi.org/10.1038/s41467-019-14215-w

Seung, C.K. (2017) A multi-regional economic impact analysis of Alaska salmon fishery failures. Ecological Economics, 138, 22-30.

Smith, C.L. and Gilden, J. (2000). Human and habitat needs in disaster relief for Pacific Northwest salmon fisheries. Fisheries, 25, 6-14.

Thompson, A.R. (2018). State of the California Current 2017-18: Still Not Quite Normal in the North and Getting Interesting in the South. California Cooperative Oceanic Fisheries Investigations. Data report, 59, 1-116.

741

742

743

744

745

746 Wernberg, T., Bennett, S., Babcock, R.C., De Bettignies, T., Cure, K., Depczynski, M., Dufois,

747 F., Fromont, J., Fulton, C.J., Hovey, R.K. and Harvey, E.S. (2016). Climate-driven regime shift

748 of a temperate marine ecosystem. Science, 353, 169-172.

749 


\section{Table $\mathbf{1}$ (on next page)}

Mixed and fixed effects formulations and parameter estimates for models of disaster occurrence and causes across years. 


\begin{tabular}{|c|c|c|c|c|c|c|}
\hline Response & $\begin{array}{l}\text { Model } \\
\text { Method }\end{array}$ & Model Formulation & Intercept(s) & Year Effect & $\begin{array}{c}\mathrm{RE} \\
\text { Variance }\end{array}$ & AIC \\
\hline $\begin{array}{c}\text { Disaster } \\
\text { Determinations }\end{array}$ & $\begin{array}{l}\text { Poisson } \\
\text { GLMM }\end{array}$ & $\begin{array}{c}\sim \text { Determination. Year }+ \\
(1 \mid \text { Management.Zone })\end{array}$ & $-0.36(0.14)$ & $\begin{array}{c}0.42(0.12) \\
\mathrm{p}<0.0008\end{array}$ & 0.014 & 226.4 \\
\hline $\begin{array}{c}\text { Disaster } \\
\text { Determinations }\end{array}$ & $\begin{array}{l}\text { Poisson } \\
\text { GLM }\end{array}$ & $\sim$ Determination. Year & $0.94(0.13)$ & $\begin{array}{c}0.38(0.13) \\
\mathrm{p}<0.003\end{array}$ & NA & 113.7 \\
\hline Ongoing Disasters & $\begin{array}{l}\text { Poisson } \\
\text { GLMM }\end{array}$ & $\begin{array}{c}\sim \text { Impact.Year }+ \\
(1 \mid \text { Management.Zone })\end{array}$ & $-0.36(0.14)$ & $\begin{array}{c}0.26(0.10) \\
\mathrm{p}<0.01\end{array}$ & 0.01 & 259.2 \\
\hline Ongoing Disasters & $\begin{array}{l}\text { Poisson } \\
\text { GLM }\end{array}$ & $\sim$ Impact.Year & $0.94(0.13)$ & $\begin{array}{c}0.38(0.11) \\
\mathrm{p}<0.0003\end{array}$ & NA & 121.3 \\
\hline Disaster Cause & $\begin{array}{l}\text { Ordinal } \\
\text { logistic } \\
\text { GLMM }\end{array}$ & $\begin{array}{c}\sim \text { Determination.Year + } \\
(1 \mid \text { Management.Zone })\end{array}$ & $\begin{array}{l}\text { NAnthropogenic|Combination of Both: - } \\
2.1(0.54) \\
\text { Combination of Both|Environmental: - } \\
0.28(0.45)\end{array}$ & $\begin{array}{c}0.94(0.27) \\
\mathrm{p}<0.0006\end{array}$ & 0.51 & 130.1 \\
\hline Disaster Cause & $\begin{array}{l}\text { Ordinal } \\
\text { logistic } \\
\text { GLM }\end{array}$ & $\sim$ Determination. Year & $\begin{array}{l}\text { Anthropogenic|Combination of Both: - } \\
1.94(0.36) \\
\text { Combination of Both|Environmental: - } \\
0.281(0.26)\end{array}$ & $\begin{array}{c}0.87(0.25) \\
\mathrm{p}<0.0004\end{array}$ & NA & 130.5 \\
\hline
\end{tabular}


8 Variance column reports the model estimated random effects variance, when appropriate. The final column reports Akaike 9 information criterion (AIC) values for each model instance. 
Figure 1

Model estimated change in the number of fishery disasters by impact year.

The dark blue line represents the maximum likelihood fit (fixed effect of year; $4^{\text {th }}$ row, table 1), while the light blue shaded regions represent the $95 \%$ confidence intervals.

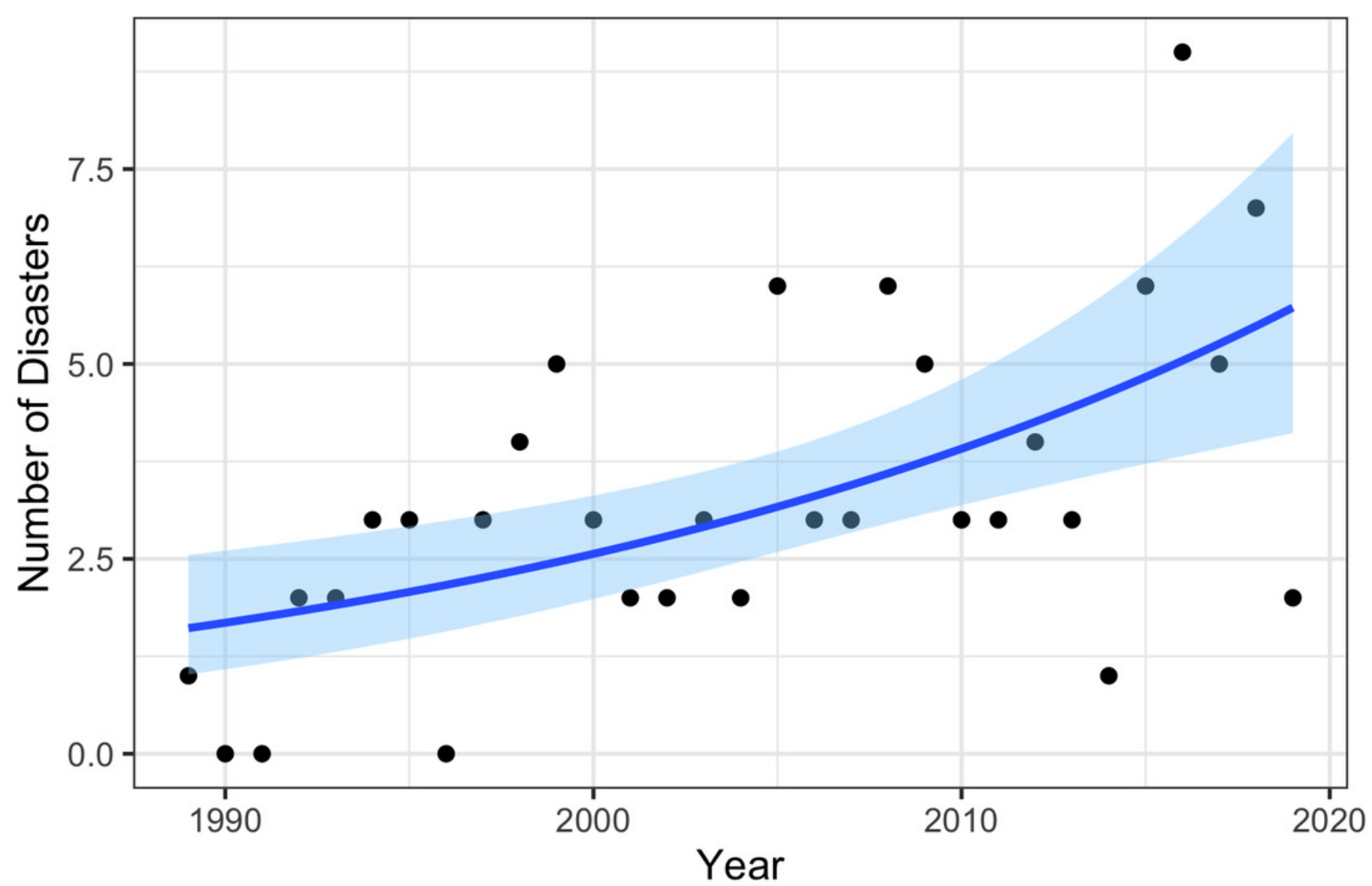




\section{Table 2 (on next page)}

Total U.S. Congressional fishery disaster assistance (2019 USD) by cause and by federal fisheries management region. 


\begin{tabular}{cccccccc} 
Cause & Alaska & $\begin{array}{c}\text { Greater } \\
\text { Atlantic }\end{array}$ & $\begin{array}{c}\text { Pacific } \\
\text { Islands }\end{array}$ & Southeast & West Coast & To be determined & Total \\
\hline \hline Anthropogenic & $\$ 82,000,000$ & $\$ 132,996,669$ & & $\$ 30,940,000$ & $\$ 7,600,000$ & & $\$ 253,536,669$ \\
Environmental & $\$ 174,292,189$ & $\$ 41,572,622$ & $\$ 1,140,000$ & $\$ 505,938,343$ & $\$ 170,723,211$ & & $\$ 893,666,365$ \\
$\begin{array}{c}\text { Combination of Both } \\
\text { To be determined }\end{array}$ & $\$ 75,588,349$ & $\$ 36,600,000$ & & $\$ 37,098,200$ & $\$ 281,802,589$ & & $\$ 431,089,138$ \\
\hline Total & $\$ 331,880,538$ & $\$ 211,169,291$ & $\$ 1,140,000$ & $\$ 573,976,543$ & $\$ 460,125,800$ & $\$ 414,103,069$ & $\$ 1,992,395,241$
\end{tabular}

Table 2. Total U.S. Congressional fishery disaster assistance (2019 USD) by cause and by federal fisheries management region. One additional disaster had an allocation amount that was not reported, but the request letter cited economic impacts of \$53.8-94.2M. Anthropogenic causes include pollution and overfishing; environmental causes include marine heatwaves, harmful algal blooms, hurricanes, extreme drought, etc.; and a combination includes both anthropogenic and environmental causes. Examples of fisheries being impacted by a combination of causes can be found in some Pacific northwest salmon fishery disasters, which were caused by low returns that resulted from marine heatwaves, drought, disease, habitat impacts, mismanagement, and overfishing. 


\section{Figure 2}

Five U.S. federal fisheries management regions (Alaska, West Coast, Pacific Islands, Greater Atlantic, and Southeast) represented in the fishery disaster database.

In each region, pie charts represent annual commercial and recreational fisheries sales impacts (top pie chart) and total number of jobs (bottom pie chart) to illustrate regional contributions to the U.S. economy. The dark shaded region in each pie chart represents commercial fishery values, and the light shaded region represents recreational fishery values (source: NOAA, 2020a).

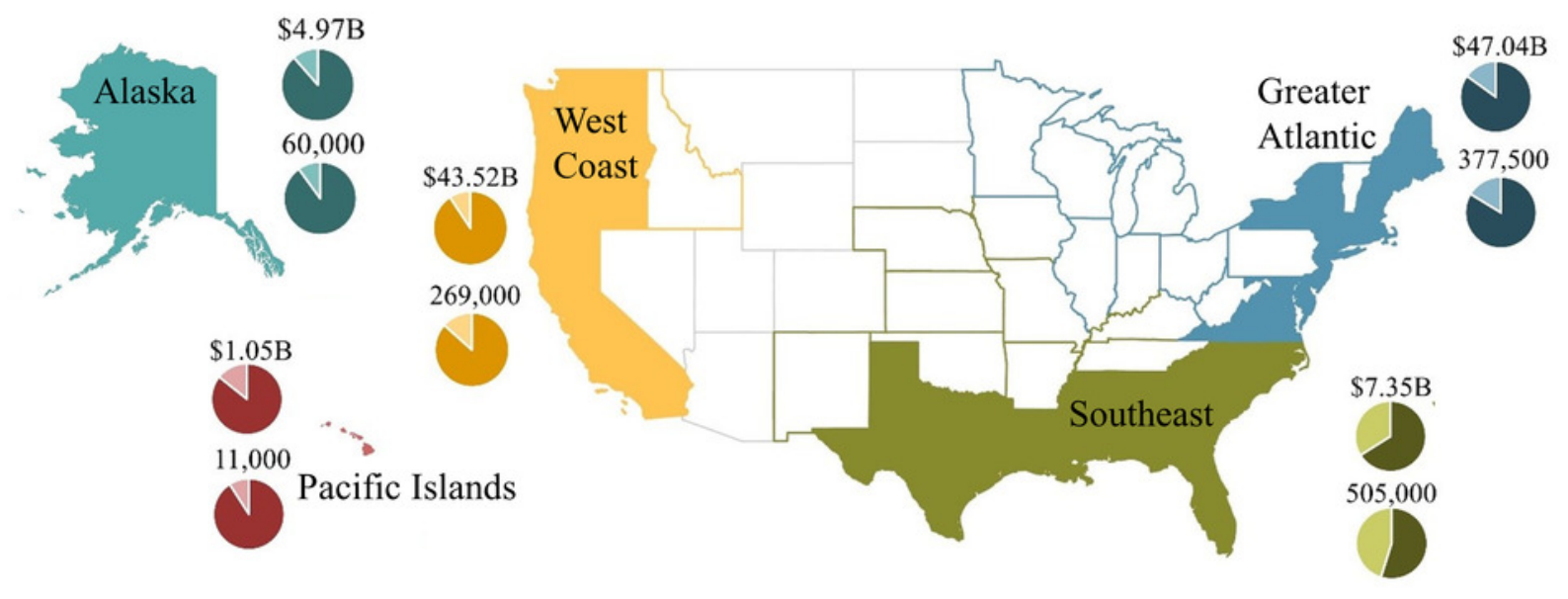




\section{Figure 3}

Federal fishery disaster request, determination, and administration process.

Agency seals represent institutional involvement during each step of the disaster assistance process. Time periods in parentheses represent the mean $( \pm S D)$ duration required for each step to occur. While the total implementation time is known (shown after step 6), some individual time steps do not have associated duration information.

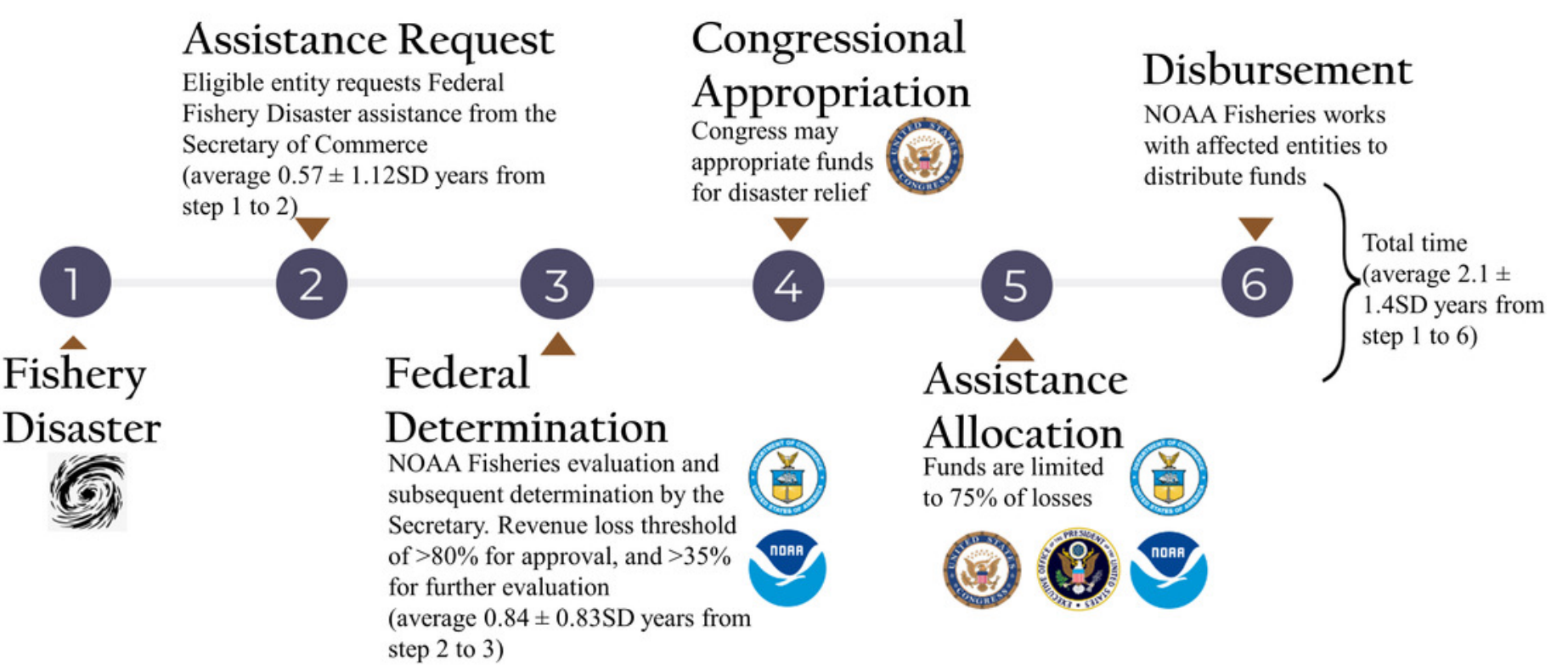




\section{Table 3 (on next page)}

Total revenue losses (2019 USD) by cause and by federal fisheries management region during disaster years. 
1

\begin{tabular}{ccccccc} 
& \multicolumn{9}{c}{ Greater } & Pacific & & \\
Cause & Alaska & Atlantic & Island & Southeast & West Coast & Total \\
\hline \hline Anthropogenic & $\$ 1,629,023,913$ & $\$ 156,252,205$ & & $\$ 19,344,227$ & $\$ 16,669,638$ & $\$ 1,821,289,983$ \\
Environmental & $\$ 460,804,419$ & $\$ 7,525,113$ & $\$ 244,000$ & $\$ 319,003,223$ & $\$ 112,420,965$ & $\$ 899,997,721$ \\
Combination of Both & $\$ 46,055,192$ & & & $\$ 5,326,946$ & $\$ 453,935,310$ & $\$ 505,317,448$ \\
\hline Total & $\$ 2,135,883,525$ & $\$ 163,777,318$ & $\$ 244,000$ & $\$ 343,674,396$ & $\$ 583,025,913$ & $\$ 3,226,605,152$
\end{tabular}

Table 3. Total revenue losses (2019 USD) by cause and by federal fisheries management region during disaster years. 
Figure 4

Model estimated change in the probability that a given disaster has roots in anthropogenic causes, environmental/anthropogenic combined causes, or environmental causes.

The dark blue center lines represent the maximum likelihood fit, while the light blue shaded regions represent the $95 \%$ confidence intervals. The rug plot (tick marks, jittered around each year) at the bottom of each panel represents the number of declared disasters (of any cause) per year.

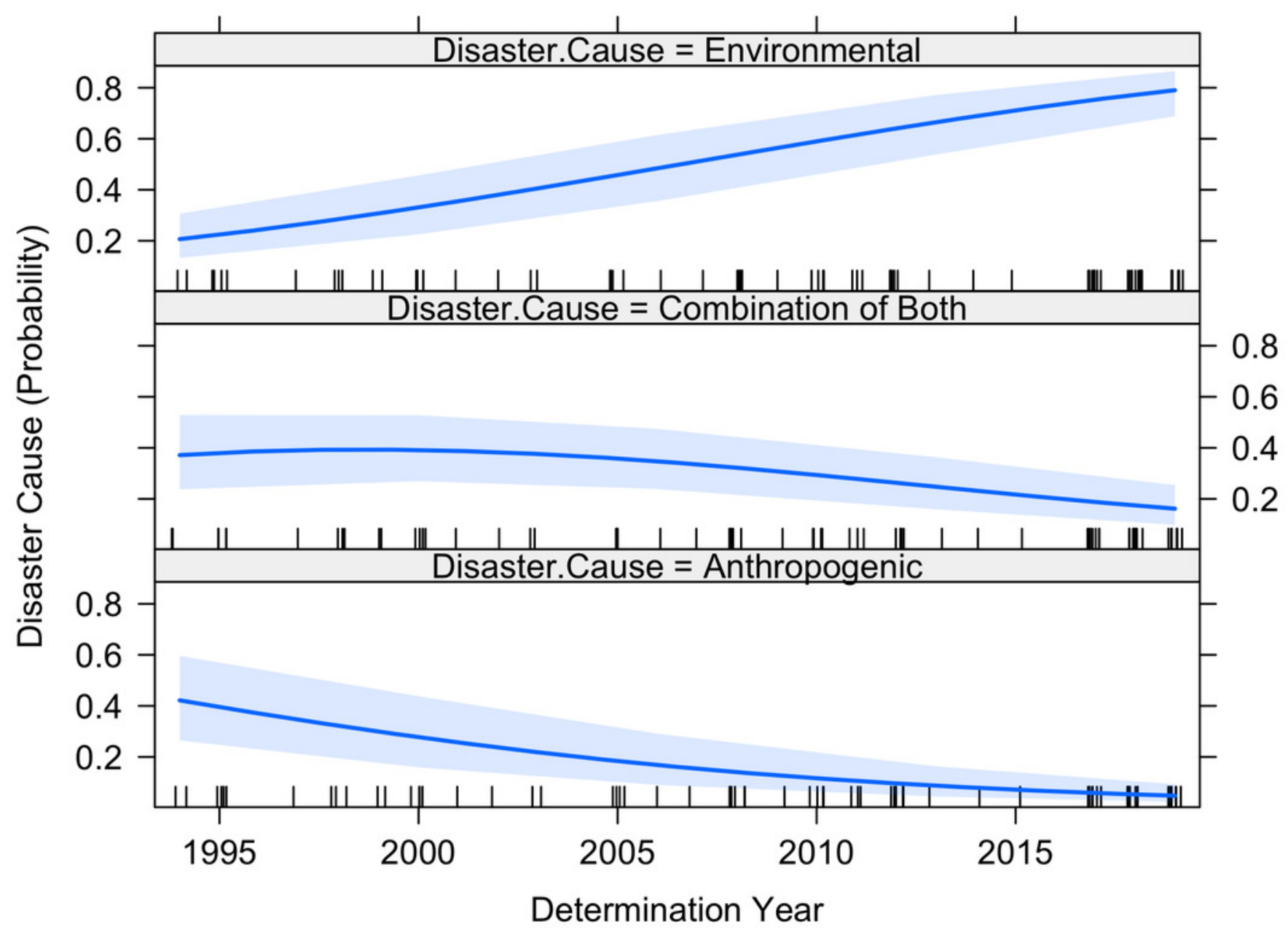

